敢确定。但無踚如何, Hedrograptus 和 Climacograplus 是有着復切关系的。此种践状构邀可能和中 軸一栟，具有考持笔存体的功用。是否代表几个質化

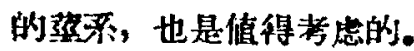

\section{李积金 剪万筹}

(中国科学院古生物研究所、西北大学地筧系) 1957 年 2 月 11 日

[1] A. М. Сбут, Полевэн Атпас Руковздящнх Граптслитов Бөрхнего Силура Киргизской ССР. “Издатөльство Киргизского Филиала АН СССР", 1949.

[2] А. М. Обут, Класс Graptolithina-Граптолиты в Пслевои Атлас Срдсвикской и Силурийской Фаукы Сибирской Платформы, 136-139, 1955.

[ 3 ] S. C. Hsu (䛈杰), The g:aptolites of the Lower Yangtze Valley. Monogr. Nat. Res. Inst. Grol., Acad. Sinica, Ser. A, Vol. IV, 1934.

\section{夏季亚洲大陆上空大 气环流的結构}

要季亚洲大陟上空，尤其是中国大随上空大坏

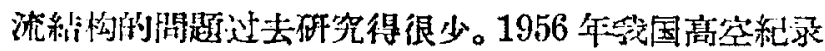

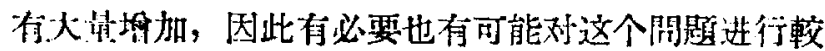
锌勫的研究。

致門根据 1951-1955 年的資料，作出了 7 月亚 洲上空 $850 、 700$ 和 500 毫巴气流綫阑以及1956 年7一

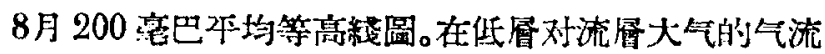
綎亥上，从北非西岸到緬甸北部有一条內热带輻合区 (intertropical convergence zone,简写为 ITC),

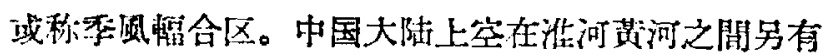

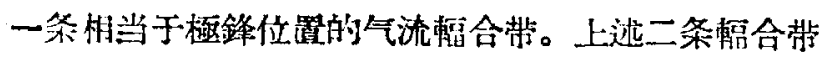

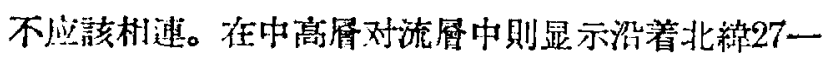
$30^{\circ}$ 有一条副热带高压带的找散軸，在这軸上出現了几 个分裂的反气旋中心，其中一个是酉藏喛高压。

由上流的流綫圖及 1956 年7-8 月沿东数 $75^{\circ}$ 、

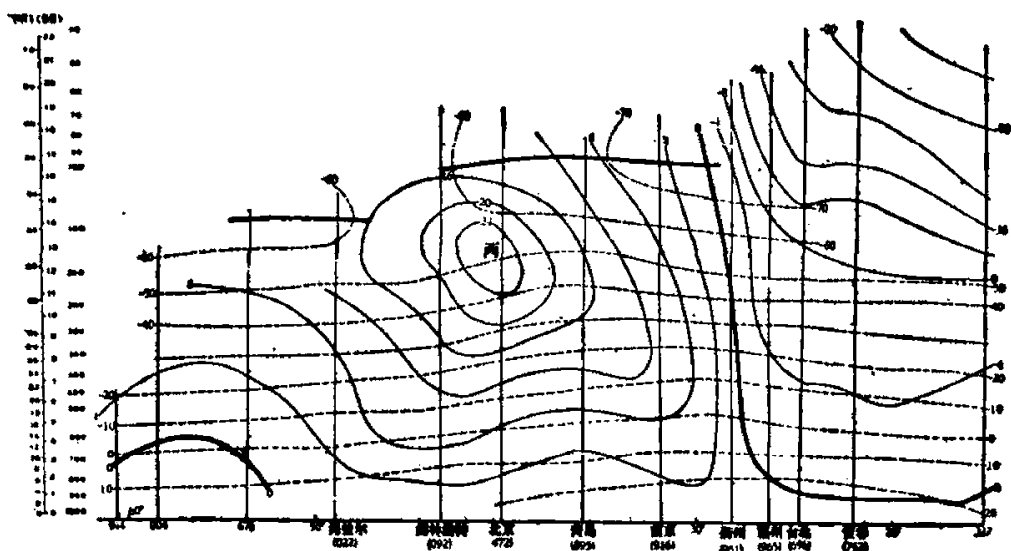

国 11956 年 7-8 月东理 $120^{\circ}$ 程綫上緯向風速(米/秒) 与盜度 ( ${ }^{\circ} \mathrm{C}$, 血絨) 剖面国

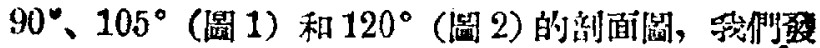

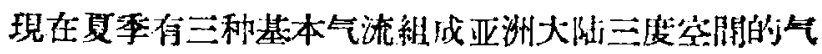
流埸, 即: (1) 中緯度西風气流: 这支西風气流出現

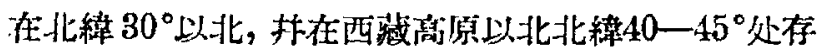
在一支酉風急流，这支急流的强度在东經 $75^{\circ}$ 处約为 40 米/秒，而在 $105^{\circ}$ 以东本均为 62 米/秒，因之它是向 下游減弱的；(2)商空热带和副热带的东風气流: 它

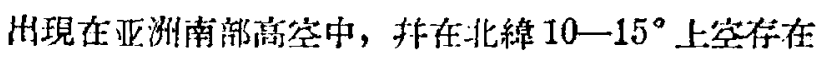

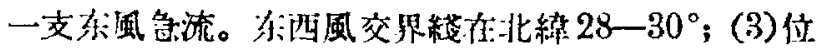

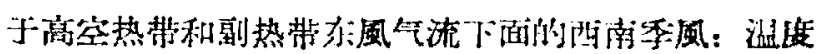

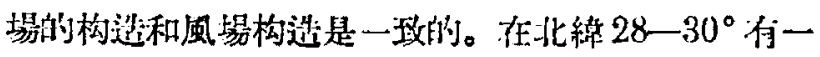

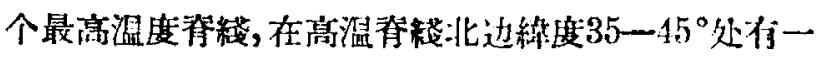

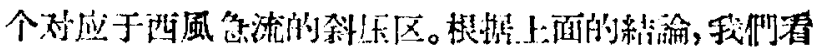

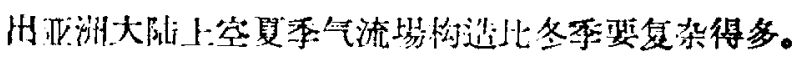

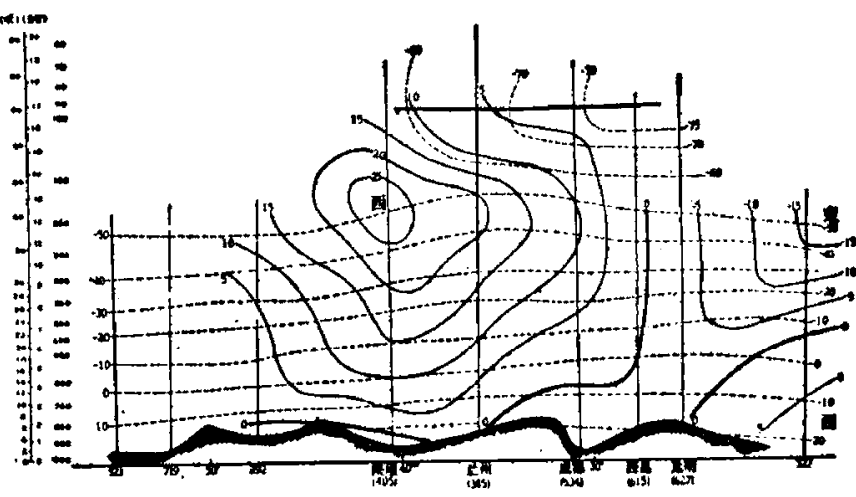

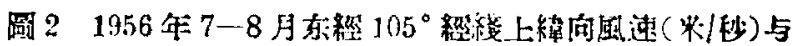

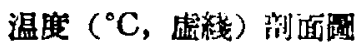

另外, 转們分析了东經 $45^{\circ} 、 90^{\circ}$ 和 $125^{\circ}$ 經悢上

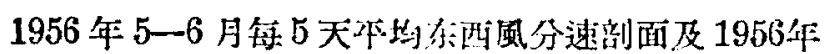

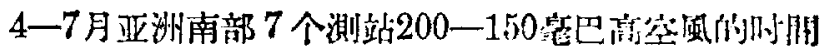

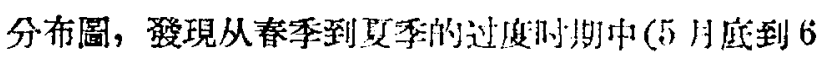

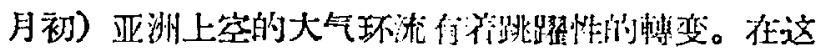

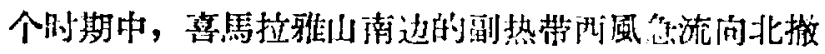

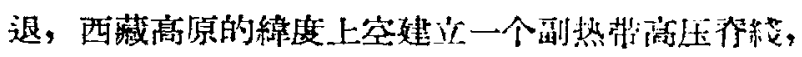

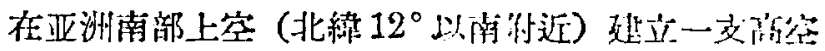

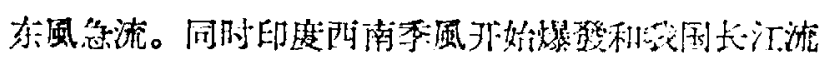

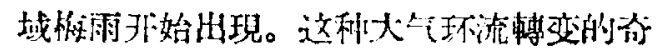
异性 (singularity) 䃑觉们助于季茫轉变

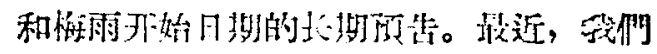

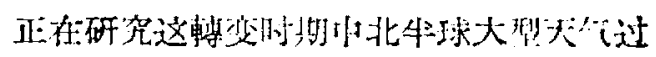
程的变化。

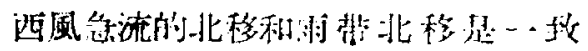

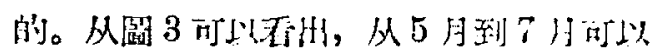

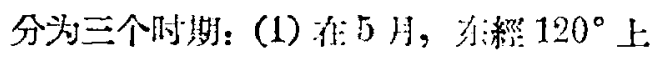

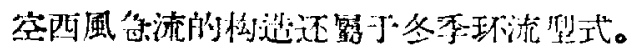

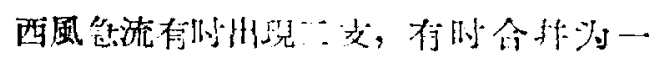

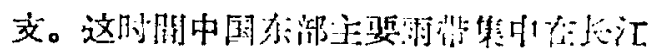

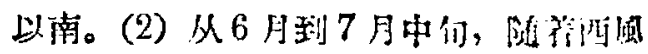




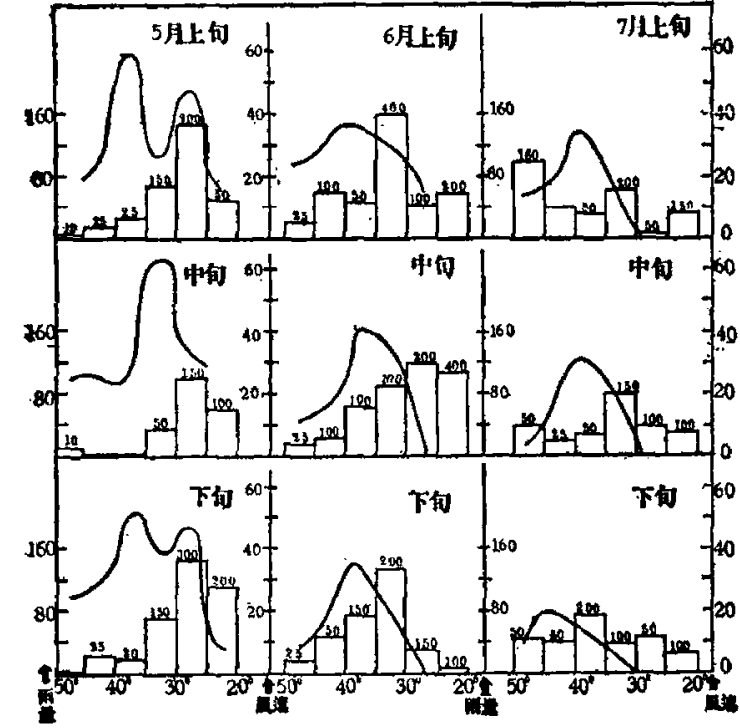

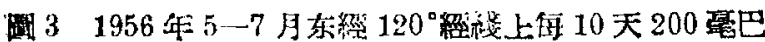

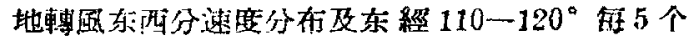
綃度地区内 10 天总降水量分布圈（长方熄上数字

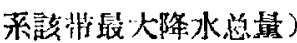

带的北移，事程 $120^{\circ}$ 上空無流只出現一支，位置在

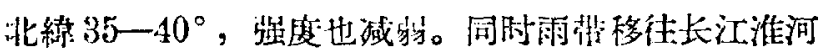

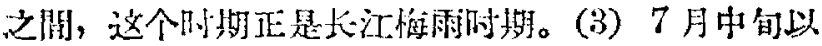

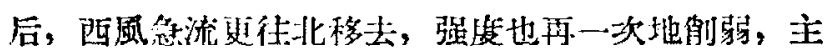

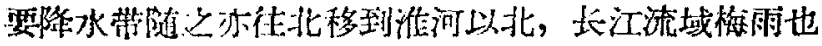
随着加邀。这则候在长江流域便进入盛夏季节。

陶詩言陈隆蚛

(中国科学院地球物理研究所)

1957 年 2 月 19 日

\section{阻塞流型發展的一个分析}

阻寒流型的水瑟是大气环流中的一种重要現象。

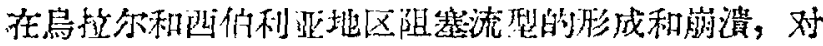

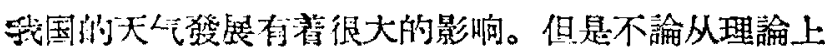
琙实际天气分析上，对阻塞流型的發展还很少定量的 研究。

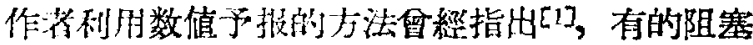

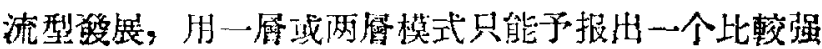

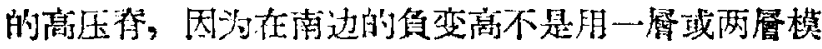
式所能予报䚾来的。在作者所研究的组空流型的發展 中，500笔巴等压面上有着相当大的輜散。此后，作

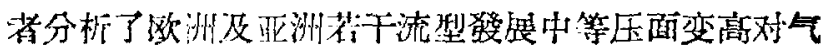

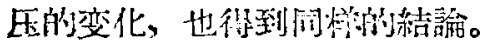

最近，瑟們用三虔谁地轉模式分析 500 毫巴傾间 的形成，了解到颌文 ${ }^{[1]}$ 所分析的例子里，在 1955 年 12 月 28 日 (03 点国际的) 到29日(03 点), 阻塞流

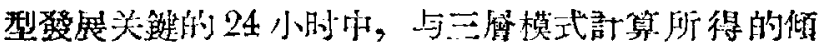

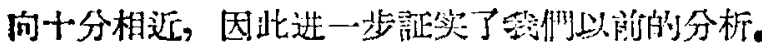

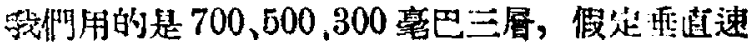

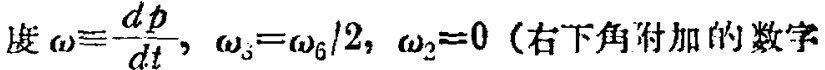
指主要等压面毫巴的百位数)。地圖投影是双标浶 $\left(30^{\circ}\right.$ 及 $60^{\circ}$ ) 兰勃脫投影，差分格子 $2 \Delta p \equiv \nu=200$ 毫巴。 $\triangle x=\triangle y \equiv \mu=375$ 公里。典美形式的洞度公式及 絕热公式得[?]:

$$
\begin{aligned}
& \Delta \tau_{3}-a_{4} \tau_{3}=-J\left(\phi_{3}, \tau_{13}\right)+\alpha_{4} \beta J\left(\phi_{5}, c_{3}\right)-\alpha_{4} \tau_{5} \\
& \Delta \tau_{5}-\left(\frac{a_{6}}{2}+a_{4}\right) \tau_{5}=-J\left(\phi_{5}, r_{5}\right)-a_{4} \tau_{5} J\left(\phi_{5}, \phi_{5}^{3}\right) \\
& +\frac{a_{i j}}{2} \beta J\left(\phi_{5}, d_{5}^{7}\right)-a_{4} \tau_{i 3}-\frac{a_{f_{i}}-\tau_{i}}{2} \\
& \Delta \tau_{7}-\frac{a_{i}}{2} \tau_{\tau}=-J\left(\phi_{7}, r_{i}\right)-\frac{a_{i}}{2} \beta J\left(\phi_{5}, \phi_{5}^{7}\right) \\
& -\frac{a_{6}}{2} \tau_{5}
\end{aligned}
$$

其中 $\triangle \psi=\Sigma \psi-4 \psi_{0}$, $\Sigma$ 攻四周四点, $a_{k}=\frac{1}{\sigma_{i j k}}\left(\frac{f \mu}{m \nu}\right)_{i, s}^{2}$ $\beta=\left(\begin{array}{c}m^{2} \\ \mu^{2} f\end{array}\right)_{i j}, \tau$ 是高度煩淌了, $f$ 是 Coriolis 奌数,

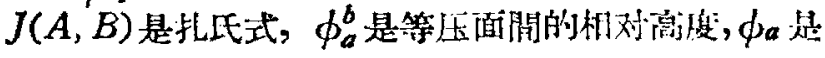

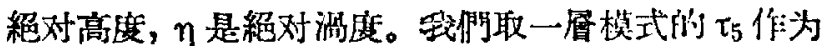
零次近似，逐次求言級近似 $\tau_{5}^{(n)}$ 。由此訃算得 28 日

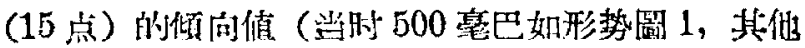

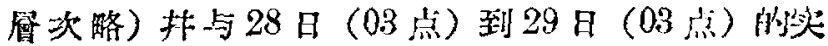

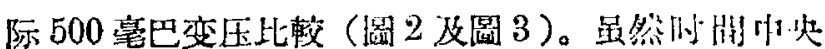
茬的間隔較长，但是两者的符合是明显的。特别是里

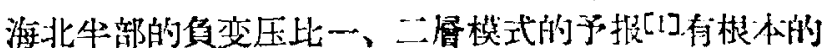
改进。

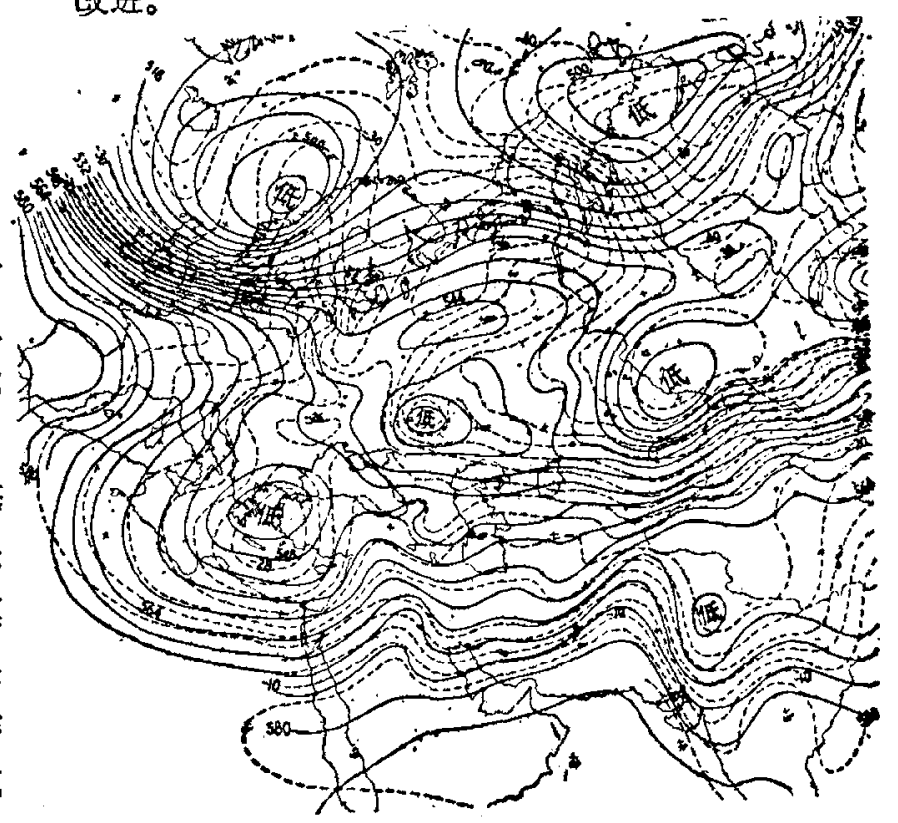

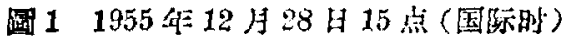

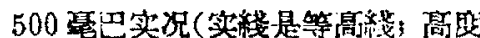

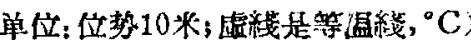

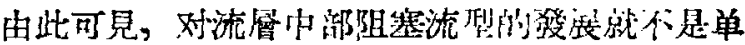

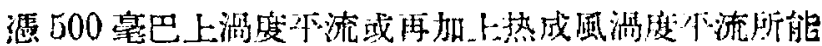
决先是的，因此不是单源这些所能报的。所以，Berg- 